\title{
Modeling Aboveground Biomass in Dense Tropical Submontane Rainforest Using Airborne Laser Scanner Data
}

\author{
Endre Hofstad Hansen ${ }^{1, *}$, Terje Gobakken ${ }^{1}$, Ole Martin Bollandsås ${ }^{1}$, Eliakimu Zahabu ${ }^{2}$ \\ and Erik Nasset ${ }^{1}$
}

1 Department of Ecology and Natural Resource Management, Norwegian University of Life Sciences, P.O. Box 5003, NO-1432 Ås, Norway; E-Mails: terje.gobakken@nmbu.no (T.G.); ole.martin.bollandsas@nmbu.no (O.M.B.); erik.naesset@nmbu.no (E.N.)

2 Department of Forest Mensuration and Management, Sokoine University of Agriculture, P.O. Box 3013, Chuo Kikuu, Morogoro, Tanzania; E-Mail: zahabue@yahoo.com

* Author to whom correspondence should be addressed; E-Mail: endre.hansen@nmbu.no; Tel.: +47-6496-5756; Fax: +47-6496-8890.

Academic Editors: Lars T. Waser and Prasad S. Thenkabail

Received: 9 September 2014 / Accepted: 7 January 2015 / Published: 14 January 2015

\begin{abstract}
Successful implementation of projects under the REDD+ mechanism, securing payment for storing forest carbon as an ecosystem service, requires quantification of biomass. Airborne laser scanning (ALS) is a relevant technology to enhance estimates of biomass in tropical forests. We present the analysis and results of modeling aboveground biomass (AGB) in a Tanzanian rainforest utilizing data from a small-footprint ALS system and 153 field plots with an area of $0.06-0.12$ ha located on a systematic grid. The study area is dominated by steep terrain, a heterogeneous forest structure and large variation in AGB densities with values ranging from 43 to $1147 \mathrm{Mg} \cdot \mathrm{ha}^{-1}$, which goes beyond the range that has been reported in existing literature on biomass modeling with ALS data in the tropics. Root mean square errors from a 10 -fold cross-validation of estimated values were about $33 \%$ of a mean value of $462 \mathrm{Mg} \cdot \mathrm{ha}^{-1}$. Texture variables derived from a canopy surface model did not result in improved models. Analyses showed that (1) variables derived from echoes in the lower parts of the canopy and (2) canopy density variables explained more of the AGB density than variables representing the height of the canopy.
\end{abstract}


Keywords: aboveground biomass; airborne laser scanning; canopy surface; LiDAR; texture variables; tropical rainforest

\section{Introduction}

Moist and wet tropical forests have the potential to store large amounts of carbon as biomass. Quantification of biomass and knowledge about its spatial distribution provides important information about the forest that is useful for ecological and environmental applications as well as forest resource management. A detailed description of forest structure will help to understand the ecological functionality of these forests [1] and how structure is governed by edaphic and climatic factors. This knowledge can be used in the development of models for local natural resource management, such as water management [2,3], or in modeling of the response of forests to climate change [4]. In some countries, timber and wood products from tropical forest are important export commodities [5] and inventories assisted by remote sensing data can provide valuable information for decision making. Even in areas in which forest products and ecosystem services are not part of a market system, forest resource information might be useful, for example for fuel wood management [6]. The carbon sequestration potential of tropical forests has received a lot of attention and has resulted in the policy and economic incentive mechanism known as REDD+. The aim of REDD+, described in the 16th session of the Conference of Parties to the United Nations Framework Convention on Climate Change, is to encourage reduction of emissions from deforestation and forest degradation, conservation and enhancement of forest carbon stocks and sustainable management of forests in developing countries [7]. Reporting of emissions from loss of forest carbon at the national level will be required [8], but many countries are likely to benefit from more local monitoring programs within the countries as well, assessing the effects of national policies and local financial mechanisms aimed at reaching goals for emission control for the nation as a whole.

Accessing carbon finances through REDD+ requires, among other factors, measurement of carbon stock changes in forests [9]. Furthermore, a mechanism for commercial trading of forest carbon credits earned through enhancement of forest carbon stocks, conservation of forests or sustainable forest management require trustworthy systems for verification of carbon offsets. In addition, application of the conservativeness principle, which takes into account the uncertainty of estimates to minimize the risk of overestimating emission reductions [10,11], and lack of accurate biomass estimates may result in loss of carbon credits for the project developer [12]. Establishing a robust and transparent system for measuring, reporting and verification (MRV) is therefore a requirement for successful implementation of a REDD+ regime [13]. A central part of such an MRV system would be the use of remote sensing data for monitoring both forest area changes and changes within forested areas [14] because remote sensing data can greatly improve the precision of estimates and change estimates of areas as well as of biomass and carbon stocks - and especially so if the remote sensing data are strongly correlated with the parameter of interest.

A variety of remote sensing technologies for determination of forest biomass exists, whereof LiDAR (light detection and ranging) sensors have been found to produce the best results in terms of 
precision $[15,16]$. The use of LiDAR, which is most commonly mounted on a small aircraft and with a scanning capability - known as airborne laser scanning (ALS) - has proven to be both effective and accurate for determining biomass in different forest types [15-17]. ALS is also used as an integral part of operational forest management inventories in several countries [18]. Most of the published studies on ALS to estimate AGB have been carried out in boreal and sub-boreal coniferous forests with relatively low biomass and open forest structure. However, in the last five years use of ALS for AGB estimation has been demonstrated in tropical forests in South America [19-23], Asia [24] and Africa [25]. The maximum biomass densities in these studies were about $500 \mathrm{Mg} \cdot \mathrm{ha}^{-1}$, while biomass densities in tropical rainforests can go far beyond $500 \mathrm{Mg} \cdot \mathrm{ha}^{-1}$.

Due to the fact that ALS does not measure biomass directly, there is a need for field data for modeling the relationship between remotely sensed observables and biomass from ground observations. The models are subsequently used for estimation of forest biomass. Taking the area-based approach [26], commonly used for ALS-based forest inventory, attributes of interest are measured or calculated from measurements on field plots and a relationship between the ALS echoes and ground attribute is determined using statistical methods such as regression analysis, nearest neighbors, neural-networks or ensemble learning. The size of field plots varies, but has usually been in the range of $0.1-1.0$ ha in tropical ALS studies.

Different types of variables are often derived from the ALS echoes and are tested to describe the relationship between the remotely sensed information and biomass. The most commonly used types of ALS-derived variables are percentiles of the height above ground above a certain threshold (canopy height variables), and fractions of echoes in the canopy to total number of echoes, including ground echoes (canopy density variables). Estimated models often include a canopy height variable describing the canopy height close to the top of the canopy or mean canopy height, in combination with a canopy density variable derived from the lower parts of the canopy, e.g., [26,27]. Alternative approaches have been to use the total canopy volume [28] or canopy height profile and canopy cover [29] calculated from the ALS echoes. The latter approach has been widely applied in tropical areas by Asner et al. [30] utilizing only one variable, namely the mean canopy profile height. Studies have documented positive relationships between AGB and forest structure diversity [31] and tree species diversity [32]. Textural information that capture structural information is commonly used in image analysis, and has been shown to be successful in modeling AGB using high-resolution satellite images [33]. Bohlin et al. [34] successfully used textural information from a canopy surface model in combination with ALS-derived height and density variables to model stem volume and basal area in Sweden. Based on these findings, we reasoned that texture variables might be able to capture information about the spatial distribution of trees and forest structure which could improve the model performance even in tropical rainforests.

When applying regression analysis, a transformation of the response and/or predictor variables is usually performed to account for non-normality and non-constant variance in the response variable. Logarithmic transformations of both response and predictor variables have been applied in several studies, e.g., [26,35]. Other strategies have been to transform the response only, and both logarithmic [24,36] and square root [19,37,38] transformations are commonly used.

In natural forests that have reached a climax state another challenge occurs when utilizing canopy height derived variables for biomass modeling. Tree height growth decreases with age, and because the decrease is stronger and starts earlier compared to a decrease in diameter growth [39], trees with 
similar crown height may have very different diameters, and thus biomass. There might even be a negative change in canopy height as trees approaches mortality and the tree crown starts to die off. Tree diameter, however, does not decrease. Thus, ALS-derived variables describing tree heights might be less correlated with AGB.

The overall objective of this study was to model AGB in a tropical forest with a wide range in AGB densities in rugged and steep terrain using ALS-derived variables. We explored the use of texture variables derived from a canopy surface model. To improve our understanding of the relationship between AGB and canopy height and density, we assessed the relative importance of different ALS-derived prediction variables.

\section{Material and Methods}

\subsection{Study Area}

The study area, Amani Nature Reserve (Figure 1) (S508', E38³7', 200-1200 m above sea level), covers around 8360 ha of tropical submontane rainforest and is located in the East Usambara Mountains in eastern Tanzania, which is a part of the Eastern Arc Mountains. The Eastern Arc Mountains is a global biodiversity hotspot area [40] and the forest, stretching from Udzungwa in Tanzania in the south to Taita Hills in Kenya in the north, contains many endemic species of both animals and plants. Within this mountain system, the East Usambara Mountains have been identified as one of three top priority areas for forest conservation [41]. In this forest ecosystem, rain falls throughout the year with two wet seasons, April to May and October to November, and the area receives around $2000 \mathrm{~mm}$ rainfall per year. Daily mean temperatures vary from about $16-25{ }^{\circ} \mathrm{C}$. Amani Nature Reserve was gazetted in 1997 comprising of six former forest reserves, Amani-East, Amani-West, Amani-Sigi, Kwamsambia, Kwamkoro and Mnyusi Scarp. In addition, forest land from the neighboring tea estate, sisal estate and local village was included in the nature reserve. The area also includes the Amani Botanical Gardens, established in 1902 under German colonial rule and have contained over 500 indigenous and non-native tree species [42]. Very few of the non-native species have successfully spread from the area in which they were planted, but one species in particular, Maesopsis eminii, is found over the whole nature reserve and is the most common species in the reserve. The $M$. eminii originate from the lake region in eastern Congo and is a typical light demanding, pioneer species. It thrives in disturbed areas, but is not able to germinate under thick canopy [43] and is not found in the less disturbed areas of the reserve. In an inventory carried out in $1986 / 87$, about half of the nature reserve was classified as logged or covered with M. eminii as a result of logging [44]. Logging was stopped in the late 1980s and most of the nature reserve is now covered by a closed forest cover. 

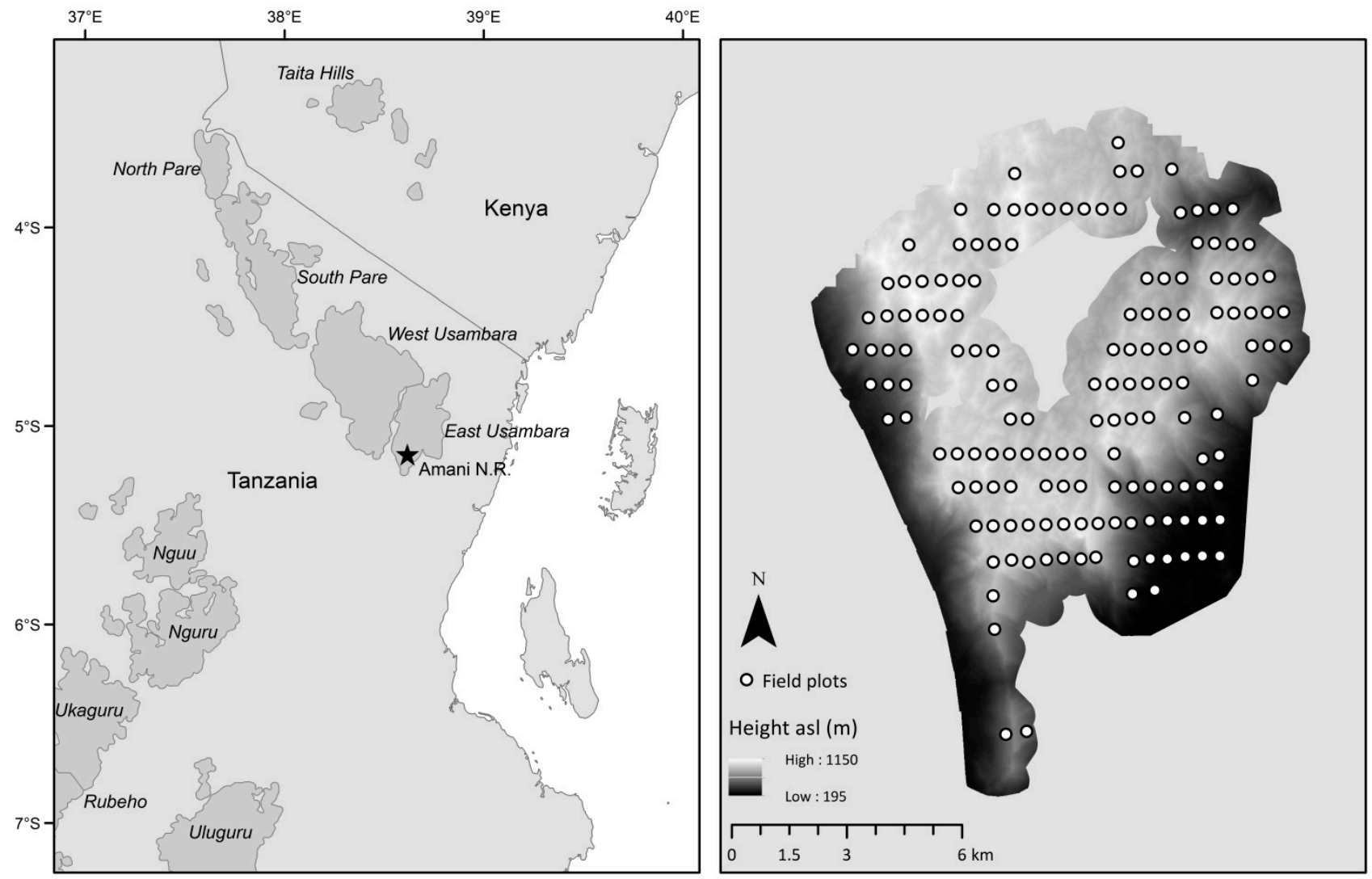

Figure 1. Left: study area (marked by star) situated in the Eastern Arc Mountains (dark grey areas). Right: field plot locations (marked by dots) inside the Amani Nature Reserve.

\subsection{Field Data}

During 1999-2000, a non-governmental conservation and development organization, Frontier Tanzania, established a grid of east/west and north/south transects for surveying flora and fauna in the reserve [45] as part of a larger biodiversity survey covering several of the tropical forest areas in Tanzania. At each crossing in the 450 by $900 \mathrm{~m}$ grid, a rectangular plot measuring $50 \mathrm{~m}$ west and $20 \mathrm{~m}$ north from the transect crossing, was established (Figure 1). The horizontal area of the plots varies from 0.0639-0.1239 ha because the plots were laid out along the terrain slope, without any slope correction. All trees with $\geq 10 \mathrm{~cm}$ diameter at breast height $(\mathrm{DBH})$ were callipered, marked and species identified. During two campaigns in 2008 and 2009/2010, 143 of these plots were revisited and all trees re-measured $[46,47]$. Trees that had grown larger than $10 \mathrm{~cm}$ in DBH since the first survey were included, and dead or missing trees excluded. All of the initial 173 plot locations were again visited during August 2011-April 2012 and plots that were not re-measured during the 2008-2010 period were re-measured this time. All plots were identified in the field by local personnel that had been doing the establishment and the previous re-measurement. Plots which were not positively identified in the field were re-established and all the trees with a $\mathrm{DBH} \geq 10 \mathrm{~cm}$ registered. This was also done for plots with an apparent change in the structure (due to landslide or human activity), or trees where added or removed where there was a clear error in the earlier records. Of the 173 plots, 15 plots had one or more corners with missing coordinates after completion of the field work due to reception of too few satellites during data recording from positioning satellites, see details below. One plot was also 
discarded because one of the processed corner coordinates had a reported error of $>10 \mathrm{~m}$. Furthermore, four plots were found to be outside the forest. The DBH data from the remaining 153 plots contain measurements from four different years; 2008 (19 plots), 2009/2010 (91 plots) and 2011/2012 (43 plots).

Ten trees per plot were selected for height measurement. The trees were systematically selected by choosing the closest tree to each corner; one tree in the middle of each short end of the plot; and two trees along the sides, $15 \mathrm{~m}$ from each corner, respectively. Tree height $(\mathrm{H})$ was measured using a Vertex IV hypsometer and trees with damage were noted. For plots with low stocking in which the same tree could be selected more than once, less than 10 heights were measured. A total of 1497 trees were measured during the fieldwork in 2011 and 2012. A summary of the field plot characteristics is presented in Table 1.

Table 1. Characteristics of 153 field plots.

\begin{tabular}{cccc}
\hline Characteristic & Range & Mean & SD \\
\hline Area (ha) & $0.0639-0.1239$ & 0.0914 & 0.011 \\
$\mathrm{~N}^{\mathbf{a}}\left(\mathrm{ha}^{-1}\right)$ & $85.4-1085.7$ & 471.5 & 161.5 \\
$\mathrm{DBH}^{\mathbf{b}}(\mathrm{cm})$ & $10.0-270.0$ & 27.5 & 22.9 \\
$\mathrm{BA}^{\mathbf{c}}\left(\mathrm{m}^{2} \cdot \mathrm{ha}^{-1}\right)$ & $5.4-144.9$ & 47.3 & 22.2 \\
$\mathrm{AGB}^{\mathbf{d}}\left(\mathrm{Mg} \cdot \mathrm{ha}^{-1}\right)$ & $43.2-1147.1$ & 461.9 & 214.7 \\
$\mathrm{H}^{\mathbf{e}}(\mathrm{m})$ & $8.3-51.3$ & 19.2 & 8.9 \\
\hline${ }^{\mathbf{a}}$ number of trees; ${ }^{\mathbf{b}}$ diameter at breast height $(1.3 \mathrm{~m})$; $^{\mathbf{c}}$ basal area; $^{\mathbf{d}}$ aboveground biomass; ${ }^{\mathbf{e}}$ predicted \\
tree height.
\end{tabular}

\subsubsection{Height-Diameter Models}

Single tree predictions of AGB with both $\mathrm{DBH}$ and $\mathrm{H}$ as independent variables in the allometric models give more reliable and lower biomass levels than without height information $[48,49]$. From the trees measured for height, a nonlinear mixed effects height-diameter (H-D) model was developed with plot as random effect. Initially, five trees with $\mathrm{H} / \mathrm{DBH}$ ratio of $<2 \mathrm{~m} / \mathrm{cm}$ were left out of the modeling. Thereafter, 20 two- and three-parameter H-D models were fit using the "fithd" function in the package "Imfor" [50] in the R software [51], and the best model form selected based on the Akaike Information Criterion (AIC). The selected model form (Equation (1)) described by Prodan [52] was then fit using the "nlme" function [53] in R, specifying $a, b$ and $c$ as random parameters because this resulted in the lowest AIC value. The selected model can be expressed as the mean (expected value) function

$$
\mathrm{E}[\mathrm{H}]=1.3+\frac{\mathrm{DBH}^{2}}{a+b * \mathrm{DBH}+c * \mathrm{DBH}^{2}}
$$

This method of calibrating the H-D model is described by Lappi and Bailey [54] and is able to include local effects. The H-D development of trees can for instance be affected by local soil conditions or by surrounding trees. The mixed effects H-D model developed from 1492 trees had a correlation between observed and predicted height (pseudo coefficient of determination $\left(\mathrm{pR}^{2}\right)$ ) of 0.75 (Table 2). To capture the local effects, field plot was specified as random effect and all three parameters of the model were allowed to describe the random effects. 
Table 2. Estimated parameters, standard deviation (SD), pseudo coefficient of determination ( $\mathrm{pR}^{2}$, correlation coefficient between observed and predicted values) and root mean square error (RMSE) for applied height-diameter model.

\begin{tabular}{ccc}
\hline Variable & Parameter estimate & SD \\
\hline $\mathrm{a}$ & 0.3376 & $(0.9032)$ \\
$\mathrm{b}$ & 0.9834 & $(0.0855)$ \\
$\mathrm{c}$ & 0.0172 & $(0.0012)$ \\
$\sigma_{a}$ & 4.9221 & \\
$\sigma_{b}$ & 0.5905 & \\
$\sigma_{c}$ & 0.0024 & \\
$\sigma_{\varepsilon}$ & 0.3485 & \\
$\mathrm{pR}^{2}$ & 0.75 & \\
$\mathrm{RMSE}$ & 5.38 & \\
\hline
\end{tabular}

\subsubsection{Aboveground Biomass}

Aboveground biomass for individual trees $\left(\widehat{\mathrm{AGB}}_{t}\right)$ was predicted using a locally developed allometric model (Equation (2)) [55]. The model is developed from 60 trees from 34 different species in the Amani Nature Reserve and has a $\mathrm{pR}^{2}$ of 0.84 . The trees were felled and green weight of stem, branches, twigs, and leaves were recorded in the field along with $\mathrm{DBH}$. Wood samples from each of the three components were collected and the green-to-dry weight ratio calculated after oven drying of the wood samples. The tree biomass was then calculated by multiplying the green weight with the green-to-dry weight ratio of each of the tree components and summed up for each tree. The applied model was

$$
\widehat{\mathrm{AGB}}_{t}=0.402 * \mathrm{DBH}^{1.4365} * \mathrm{H}^{0.8613}
$$

where $\widehat{\mathrm{AGB}}_{t}$ is the predicted aboveground biomass in $\mathrm{Mg}$ for individual tree number $t, \mathrm{DBH}$ is the tree diameter at breast height in $\mathrm{cm}$ and $\mathrm{H}$ is the tree height in $\mathrm{m}$. The $\widehat{\mathrm{AGB}}_{t}$ was then summed on field plot level and weighted to per hectare unit by the plot area (Table 1).

\subsubsection{Positioning of the Field Plots}

During the revisit of the field plots in the period August 2011-April 2012, the plot corners were georeferenced by means of differential global positioning system (GPS) and global navigation satellite system (GLONASS) using a 40-channel dual frequency survey grade receiver as field unit. A second receiver, acting as a base station, was placed on the roof of a house at the Amani Nature Reserve headquarters with a distance of $<14 \mathrm{~km}$ from the plots. Before the positioning of the plots started, the coordinates of the base station antenna was determined with Precise Point Positioning with GPS and GLONASS data collected continuously for $24 \mathrm{~h}$ according to Kouba [56]. The field unit was placed at each corner of each plot on a $2.9 \mathrm{~m}$ rod for a minimum of $30 \mathrm{~min}$, and a one second logging rate was used. Planimetric errors of the plot corner coordinates were estimated to an average of $57 \mathrm{~cm}$ based on random errors reported from the post-processing using Pinnacle software [57] and empirical experience of the relationship between reported error and the true error documented by Næsset [58]. 


\subsection{ALS Data}

Airborne laser scanning with complete coverage was performed using a Leica ALS70 sensor mounted on a Cessna 404 twin engine, fixed wing aircraft. The acquisition was carried out in the period 19-25 January 2012 with additional flights in the period 2-18 February 2012 to fill minor gaps in the data. Average flight speed was $70 \mathrm{~m} \cdot \mathrm{s}^{-1}$ at a mean flying altitude of $800 \mathrm{~m}$ above ground level and with a laser pulse repetition frequency of $339 \mathrm{kHz}$. From each pulse, the sensor registered up to five echoes. A maximum scan angle of $\pm 16^{\circ}$ from nadir yielded an average swath width of $460 \mathrm{~m}$. The beam divergence was $0.28 \mathrm{mrad}$ which produced an average footprint size on the ground of about $22 \mathrm{~cm}$. Following the acquisition, a post processing was performed by the contractor (Terratec AS, Norway). Echoes reflected from the ground were identified and classified using the progressive triangulated irregular network (TIN) densification algorithm [59] of TerraScan software [60]. An ALS terrain model was created as a TIN from the planimetric coordinates and corresponding heights of the ALS echoes classified as ground echoes. The TIN model was then used to calculate the height relative to the ground for all echoes by subtracting the TIN model height from the height of the echoes. ALS echoes classified according to Anon. [61] as "overlapping", "low", and "error" were omitted, resulting in an average pulse density of 10 echoes $\cdot \mathrm{m}^{-2}$. From the five echoes registered per pulse, we used only echoes of the three categories "single", "first of many", and "last of many". Single and first of many were merged into one dataset and denoted as "first echoes" while single and last of many were merged into another dataset and denoted as "last echoes".

ALS data for the canopy layer were extracted for each field plot, and a number of variables describing the vertical distribution of ALS echoes (vertical variables) were derived from the height distribution of echoes for each of the two echo categories (first, last). Vertical variables were further divided into variables describing the height (canopy height variables) and density (canopy density variables) of the forest canopy. Canopy height variables including maximum- and mean values (Hmax, Hmean), standard deviation (Hsd), coefficients of variation (Hcv), kurtosis (Hkurt), skewness (Hskewness) and percentiles at 10\% intervals (H10, H20,..., H90) were derived from the laser echoes above a threshold of $4 \mathrm{~m}$ above ground. It has been common in boreal forests to use a threshold of $2 \mathrm{~m}$ to distinguish between the tree layer and below-canopy vegetation [26,62], however, the minimum DBH of $10 \mathrm{~cm}$ and the overall size of the trees sampled justify the higher threshold of $4 \mathrm{~m}$. In addition to the canopy height variables, canopy density variables were derived by dividing the height between a 95\% percentile height and the $4 \mathrm{~m}$ threshold into 10 equally tall vertical layers and calculating the proportion of echoes above each layer to the total number of echoes of each echo category (first, last), including echoes below the $4 \mathrm{~m}$ threshold (D0, D1,.., D9). To denote if the variables were derived from the first or last echo category, a subscript L or F was used as notation, e.g., Hmean.F.

Variables describing horizontal distribution of the ALS canopy echoes, texture variables, were also computed. Firstly, a rasterized canopy surface model of $1 \mathrm{~m}$ resolution was computed from the top-of-canopy echoes. The raster was then converted into grey level images and variables originally presented by Haralick et al. [63] were calculated using the "glcm" package [64] in R. The texture variables were calculated using a $3 \mathrm{~m}$ window size and averaged in all directions $\left(0,45,90\right.$ and $\left.135^{\circ}\right)$. The window size of $3 \mathrm{~m}$ was chosen because a 3 pixel window was the smallest available in the "glmc" package, and we considered that larger window sizes would provide less detailed metrics. 
Shifts of 3, 6, 9, 12 and $15 \mathrm{~m}$ were tested and variables included mean (MN), homogeneity (HG), variance (VAR), contrast (CONT), dissimilarity (DS), entropy (ENT), angular second moment (SM) and correlation (COR) for each of the shifts. As an example MN.15 is the average of the height of the $3 \mathrm{~m}$ windows with a distance of $15 \mathrm{~m}$ between each window in all directions.

\subsection{Multiple Regression Analysis}

Different linear least-square multiple regression models for AGB were developed using vertical variables, texture variables and a combination of both vertical and texture variables (Table 3). Two alternative transformations of the response variable, logarithmic and square root were also performed for each set of predictor variable type (Table 3). For models A-C for which logarithmic transformations were applied, the transformation of the response variable introduced a bias when back-transformed to arithmetic scale. The models were therefore adjusted for logarithmic bias according to Goldberger [65] by adding half of the model mean square error to the constant term before transformation to arithmetic scale. For models D-F, with square root transformed response, the models were back-transformed according to Gregoire et al. [66] by squaring the prediction and adding the model mean square error.

Predictor variable selection was performed using a best subset regression procedure implemented in the "leaps" package [67] in R. The models were selected based on the Bayesian information criterion (BIC), allowing up to five predictor variables. To avoid multicollinearity the variance inflation factors (VIF) were controlled. For the selected model, a 10-fold cross-validation was performed, and assessment of accuracy was done by estimating the RMSE (Equation (3)) and mean difference $(\bar{D})$ (Equation (4)):

$$
\begin{aligned}
\text { RMSE } & =\sqrt{\frac{\sum_{i=1}^{n}\left(\widehat{y}_{l}-y_{i}\right)^{2}}{n}} \\
\overline{\mathrm{D}} & =\frac{\sum_{i=1}^{n}\left(\widehat{y}_{l}-y_{i}\right)}{n}
\end{aligned}
$$

where $n$ is number of plots, $y_{i}$ is the observed value for plot $i, \hat{y}_{i}$ is the predicted value for plot $i$. The relative RMSE (RMSE\%) and relative $\overline{\mathrm{D}}(\overline{\mathrm{D}} \%)$ were calculated as a percentage by dividing the absolute RMSE and $\overline{\mathrm{D}}$, respectively, by the observed mean.

Table 3. Summary of tested model forms and predictor variables.

\begin{tabular}{ccc}
\hline Model & Transformation & Predictor variables \\
\hline A & Logarithmic & Vertical \\
B & Logarithmic & Texture \\
C & Logarithmic & Vertical + Texture \\
D & Square root & Vertical \\
E & Square root & Texture \\
F & Square root & Vertical + Texture \\
\hline
\end{tabular}




\subsection{Analysis of ALS Variables}

In a natural forest that has reached a climax state, and where the height growth of some of the trees has stopped, the asymptotical H-D relationship will introduce problems when using ALS variables derived from canopy height for predicting AGB. The canopy height information is likely to be less correlated with the response variable of interest so that variables capturing other features-for example canopy density - could be better suited as predictor variables. The diversity in forest structure expressed by texture variables could also provide important information for AGB prediction.

To explore the relative importance of the predictor variables, an analysis was performed by fitting a separate simple linear model for a random sample of $1 / 3$ of the plots. The single predictor variable resulting in the lowest BIC value was included in the model. Random sampling of observations, performed without replacement and model-fitting was repeated 1000 times. The rate of how often each variable appeared in the model was used as a measure of importance for each individual variable.

\section{Results}

Results for the six different models are presented in Table 4. Models with logarithmic and square root transformations of the response perform equally well, with an RMSE of estimated values of around $33 \%$ of a mean value of $462 \mathrm{Mg} \cdot \mathrm{ha}^{-1}$ for both transformations. Multicollinearity was controlled by checking the VIF of the models. All models had a VIF value below 3. Models developed using vertical variables only (A and $D$ ) included three variables and variables describing the height and density of the forest canopy. Use of texture variables only did not perform as well as the standard vertical variables. The modeling procedure selected only one and two texture variables for models B and $\mathrm{E}$, respectively.

In combination with the vertical variables, only MN.15 was selected together with vertical variables in model $\mathrm{C}$. The cross-validation procedure generally resulted in overestimated AGB values of observation in the range of $200-500 \mathrm{Mg} \cdot \mathrm{ha}^{-1}$ and underestimation of observation of above $500 \mathrm{Mg} \cdot \mathrm{ha}^{-1}$ (Figure 2).

Table 4. Summary of regression models for aboveground biomass (AGB) using ALS variables.

\begin{tabular}{|c|c|c|c|c|c|c|c|c|}
\hline \multirow{2}{*}{ Model } & \multirow{2}{*}{$\begin{array}{l}\text { Response } \\
\text { Variable }\end{array}$} & \multirow{2}{*}{ Predictive Model a } & \multicolumn{2}{|c|}{ Model Fit } & \multicolumn{4}{|c|}{ 10-Fold Cross-Validation b } \\
\hline & & & $\mathbf{R}^{2}$ & BIC & RMSE & RMSE\% & $\overline{\mathbf{D}}$ & $\overline{\mathbf{D}} \%$ \\
\hline A & $\ln \mathrm{AGB}$ & $\begin{array}{c}3.815+1.755 \mathrm{D} 2 . \mathrm{L}+1.498 \cdot \mathrm{D} 9 . \mathrm{L} \\
+0.016 \mathrm{H} 90 . \mathrm{F}\end{array}$ & 0.70 & 98.8 & 149.18 & 32.3 & -2.40 & 0.5 \\
\hline B & $\ln \mathrm{AGB}$ & $3.984+3.222$ MN.3 & 0.52 & 160.6 & 173.84 & 37.6 & -8.57 & 1.9 \\
\hline $\mathrm{C}$ & $\ln \mathrm{AGB}$ & $\begin{array}{c}3.665+1.530 \mathrm{D} 2 . \mathrm{L}+1.231 \cdot \mathrm{D} 9 . \mathrm{L} \\
+0.013 \mathrm{H} 90 . \mathrm{F}+0.737 \mathrm{MN} .15\end{array}$ & 0.71 & 98.7 & 158.02 & 34.4 & -2.85 & 0.6 \\
\hline $\mathrm{D}$ & $\operatorname{sqrt}(A G B)$ & $\begin{array}{c}3.796+11.294 \text { D2.L }+ \\
13.321 \cdot \text { D9.L }+0.249 \text { Hmean.L }\end{array}$ & 0.62 & 814.4 & 154.44 & 33.4 & 6.12 & 1.3 \\
\hline
\end{tabular}


Table 4. Cont.

\begin{tabular}{|c|c|c|c|c|c|c|c|c|}
\hline \multirow{2}{*}{ Model } & \multirow{2}{*}{$\begin{array}{l}\text { Response } \\
\text { Variable }\end{array}$} & \multirow{2}{*}{ Predictive Model a $^{2}$} & \multicolumn{2}{|c|}{ Model Fit } & \multicolumn{4}{|c|}{ 10-Fold Cross-Validation b } \\
\hline & & & $\mathbf{R}^{2}$ & BIC & RMSE & RMSE\% & $\overline{\mathbf{D}}$ & $\overline{\mathbf{D}} \%$ \\
\hline $\mathrm{E}$ & $\operatorname{sqrt}(A G B)$ & $\begin{array}{c}7.563+0.054 \mathrm{MN} .3 \\
-0.072 \cdot \mathrm{CONT} .3\end{array}$ & 0.48 & 857.0 & 169.77 & 36.8 & 8.17 & 1.8 \\
\hline $\mathrm{F}$ & $\operatorname{sqrt}(A G B)$ & $\begin{array}{c}3.796+11.294 \text { D2.L }+ \\
13.321 \cdot \mathrm{D} 9 . \mathrm{L}+0.249 \text { Hmean.L }\end{array}$ & 0.62 & 814.4 & 156.59 & 33.9 & 5.57 & 1.2 \\
\hline
\end{tabular}

Notes: ${ }^{\mathbf{a}}$ Variables explained in Section 2.3.; ${ }^{\mathbf{b}}$ Values after back transformation to arithmetic scale.
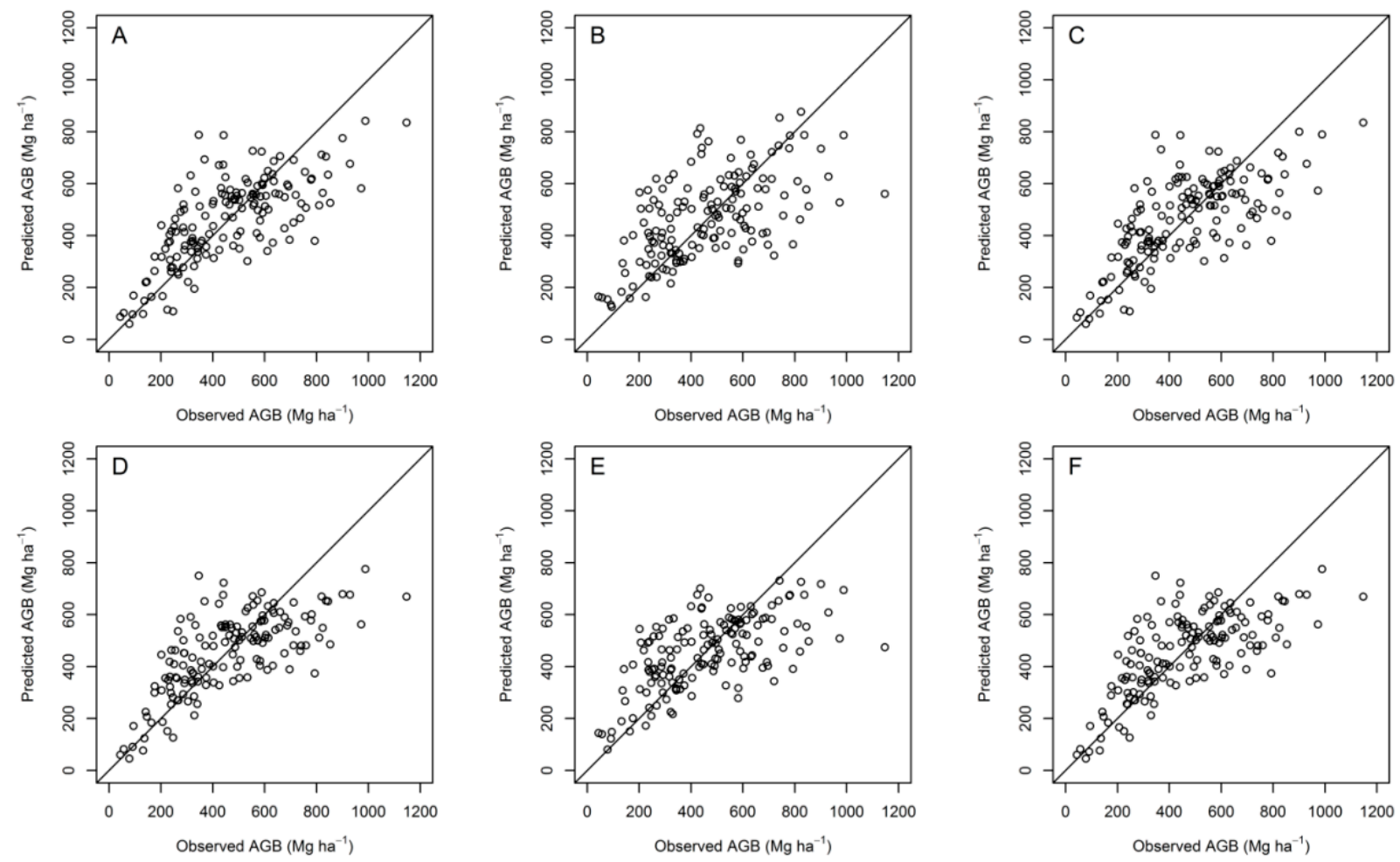

Figure 2. Scatter plots of observed versus predicted aboveground biomass (AGB) using logarithmic (A-C) or square root transformations of the response (D-F) in combination with vertical variables $(A, D)$, texture variables $(B, E)$ and both vertical and texture variables $(\mathrm{C}, \mathrm{F})$.

The analysis of the relative importance (Section 2.5) of the variables used to estimate AGB generally showed that density variables from the lower parts of the forest canopy and from the last echo category were frequently selected. For logarithmic transformation with both vertical and texture variables, D1.L, D2.L and D3.L were the most frequently selected variables and they were selected in $52 \%$ of the models. D1.F, D2.F and D3.F were selected in $22 \%$ of the models. Canopy height variables are less frequently selected and only Hmean.L and H30.L feature among the 10 most selected variables with a frequency of $9 \%$ and $4 \%$, respectively. The most frequently selected texture variable was MN.3, which also is an expression of the mean canopy height and was selected in $2 \%$ of the models. The nine most frequently selected variables for each model strategy are presented in Figure 3. 

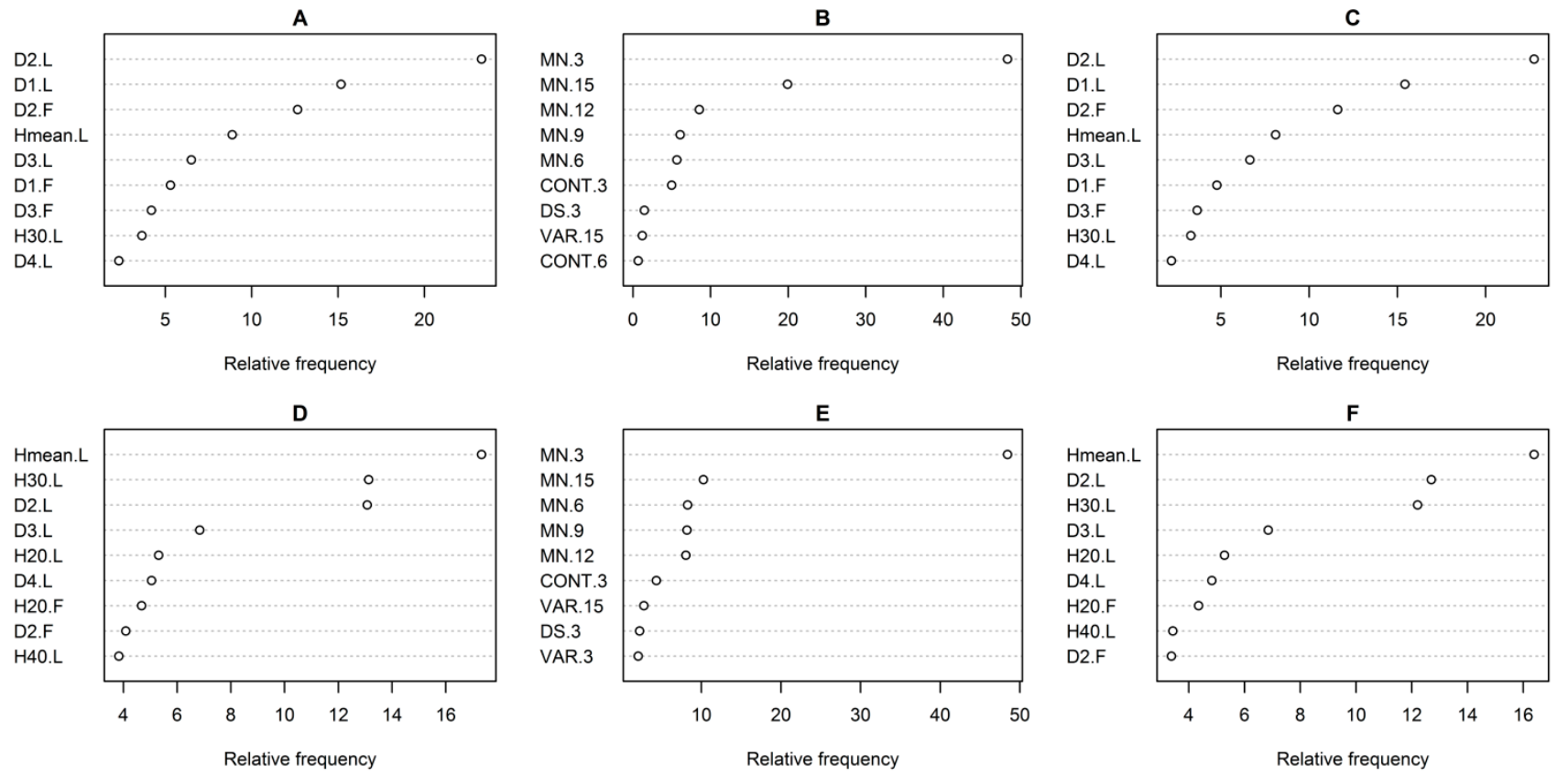

Figure 3. Dotchart of the relative frequency of the nine most frequently selected predictor variables in a simple linear model fitting procedure with logarithmic $(\mathbf{A}-\mathbf{C})$ and square root transformation of the response (D-F) in combination with vertical variables (A, D), texture variables $(\mathrm{B}, \mathrm{E})$ and both vertical and texture variables $(\mathrm{C}, \mathrm{F})$. Variables are explained in Section 2.3.

\section{Discussion}

From a REDD+ perspective, it is important to establish a robust and transparent system for estimating carbon stocks in all types of forest. The dataset used in this study is from a unique submontane tropical rainforest with a wide range in biomass densities and very high maximum levels of biomass. Regression models for AGB were developed with ALS-derived variables as predictors. The size of each plot (0.0639-0.1239 ha, Table 1) corresponds well with sizes that have been used frequently in forest sample surveys in tropical countries $[68,69]$. The plot size is smaller than what has been common practice in more ecologically oriented studies [70], and the wide range in AGB is a direct consequence of the limited plot size. Marshall et al. [48] reported a maximum AGB of about $600 \mathrm{Mg} \cdot \mathrm{ha}^{-1}$ on 1-ha plots from the same forest area in Tanzania as in our study. In temperate areas the use of LiDAR has been shown to aid successful estimation of biomass up to $1200 \mathrm{Mg} \cdot \mathrm{ha}^{-1}[29,71]$, and even though the mentioned studies applied large footprint full waveform LiDAR systems and the forest structure was very different (coniferous forest dominated by Douglas fir (Pseudotsuga menziesii)), this has set a standard for what could be achieved with the technology. In comparison to other studies, our results in terms of RMSE for estimated AGB are within in the ranges of what has been found in tropical forest areas. Clark et al. [19] reported an RMSE of 33\% using small-footprint ALS and a field plot size of 0.09 ha in old-growth and managed tropical forest in Costa Rica. In the study by Asner et al. [30] findings in terms of RMSE\% from Hawaii, Peru, Panama and Madagascar were $32 \%, 24 \%, 18 \%$ and $35 \%$, respectively. Some caution should be exercised though, when comparing with other studies, especially with the one reported by Asner et al. [30], because the latter 
study covered a smaller AGB range than our data and the reference plot size was larger, ranging from 0.1-0.36 ha. Studies based on large field plots will report lower RMSE due to spatial averaging as larger field plot sizes will decrease between-plot variance (cf. [72,73]). That means that all field observations will be more similar, covering a smaller range, and closer to the average value. In addition, larger plots have smaller ratios of the border zone to total plot area than smaller plots-a zone which is subject to edge effects $[73,74]$. This implies that the relative influences of edge effects are smaller for larger plots, regardless of plot shape. Negative consequences of GPS positioning errors are also smaller for large plots [72]. Likewise, edge effects will be more pronounced in forests with large tree crowns and for rectangular or quadratic plots than circular plots with a smallest possible circumference-to-area ratio.

Even though larger field plots result in models with better performance [16,73], the practical application is limited due to the difficulty of establishing larger field plots, i.e., plots larger than, say, 0.25 ha. This is especially challenging in rugged and steep terrain, and in areas with very dense vegetation. Reducing the field plot size to a more practical and manageable size like in our case will however introduce more edge effects and reduced accuracy of model predictions, as indicated above. Circular plots - as opposed to rectangular plots that were used in this study-will have a smaller circumference-to-area ratio and thus reduce the edge effects and improve the results. It is clear though, that inventory applications, assuming support of ALS data in the estimation, will profit from larger plots than what traditionally have been used in pure field-based sample surveys in the tropics.

Measuring the height of trees is increasingly difficult as tree height increases because (1) an offset in the registered angle results in larger errors in absolute values and (2) the domed shapes and wide tree crowns, common for large and emergent trees, also increase the difficulty of determining the true top of the tree. Because of the dense vegetation in many tropical forests one is forced to stand relatively close to the tree when measuring the tree height. This increases the effect of both (1) and (2). Our H-D model accuracy is in line with the results reported by others, both in Tanzania [75] and other tropical areas [39]. However, the error in the H-D model will propagate and introduce errors in the field estimated AGB, reducing the fit of the AGB models.

Co-registration errors, i.e., the mismatch between the positioning of the field plots and the ALS data, will also add to the total error of the AGB LiDAR models. Although the reported precision of the plot corner coordinates was $57 \mathrm{~cm}$, the true accuracy is unknown, but probably lower (cf. [76]).

The time lag between the field inventory and the ALS survey will also introduce errors in the models. Most of the trees will increase in AGB, and some might die. We tried to correct for some of the most extreme changes (like tree mortality) during the field inventory. There are however most likely still errors in the data caused by the time lag that were not accounted for.

Forest canopy height and density are correlated with AGB, and ALS-derived variables describing the canopy height and density are useful for modeling forest AGB. In addition, forest structural diversity is positively correlated with AGB [31], and use of ALS-derived horizontal information has been explored for estimation of forest variables [34,77] and silvicultural treatment needs [78]. Bohlin et al. [34] found a small but significant improvement with inclusion of textural information in modeling forest volume and basal area in a coniferous forest in Sweden. Li et al. [77] tested a new ALS-derived horizontal variable in a Chinese spruce forest for biomass estimation and found it to improve the models at tree level. However, area-based estimates did not improve. It should be noted 
that the previous studies were conducted in coniferous forests with relatively low structural diversity. We proposed that by adding textural variables, describing horizontal distribution of forest canopy, we would capture information about the spatial distribution of trees and of the forest structure which could improve the model performance. The result of including textural variables derived from an ALS surface model was; however, negative. None of the textural variables were selected in the multiple regression variable selection routine.

In a natural forest that has reached a climax state and in which some of the largest trees have reached their maximum height, the canopy height information from the ALS echoes will provide less information about the AGB. Because of the asymptotic relationship between height and diameter, canopy height variables are less suitable to discriminate between tall trees with various diameters. It is generally the large trees in a tropical forest that show this asymptotic H-D development $[79,80]$ and since these trees have great influence on the AGB in our field plots, this effect could also explain the underestimation for the plots with the higher AGB values. Similar observations were made by Skowronski et al. [81] in a temperate forest with asymptotic relationship between height and diameter. Our analysis of the relative importance of the ALS variables showed that most of the information for explaining AGB is found in the variables describing the vertical density of the full vegetation layer, and in variables from the last return echoes. The height of the trees and the density of the vegetation in higher levels of the vegetation provide less explanatory power supporting the notion that the height information is less informative than the density of the forest in a high-biomass tropical forest in which the largest trees have reached their maximum height.

\section{Conclusions}

In this study, we modeled AGB in a dense tropical rainforests using ground observations from 153 relatively small field plots of $0.0639-0.1239$ ha, and ALS-derived variables. The RMSE of the models was approximately $33 \%$ of the mean value of $462 \mathrm{Mg} \cdot \mathrm{ha}^{-1}$. This result is similar to earlier studies in tropical rainforest areas. The AGB range however is larger than reported in previous studies. We explored the use of texture information derived from a canopy surface model and anticipated that these variables would capture information about the forest structure useful for modeling forest AGB. However, none of the texture variables were selected in models in which all predictor variables were available. The single most important variable available among the texture variables was MN.3, describing the mean canopy height on a $3 \mathrm{~m}$ spatial scale, which expresses much the same information as a mean canopy profile height. Nevertheless, this variable did not add new information to the models. Furthermore, analyses of the ALS variables showed that the most important variables were derived from the last echo category, from the lower parts of the canopy, and that they were variables describing the density of the forest canopy. This finding indicates that ALS-derived variables are less able to pick up on information about AGB in a natural forest in which a proportion of the trees has a reduced or even negative height and crown development.

The findings in the present study demonstrate the power of utilizing ALS data even in extreme conditions in dense tropical forests. However, the results also identified some challenges related to field plot size, plot edge effects and tree height-biomass relationship that warrant further research in this valuable biome. 


\section{Acknowledgments}

This work is part of the project "Enhancing the measuring, reporting and verification (MRV) of forests in Tanzania through the application of advanced remote sensing techniques" funded by the Royal Norwegian Embassy in Tanzania as part of the Norwegian International Climate and Forest Initiative. Tree DBH data from 2008 to 2010 were provided by project "Assessing the impact of forestland tenure changes on forest resources and rural livelihoods in Tanzania" under the Tanzania-Norway NUFU program. We wish to thank Terratec AS, Norway, for acquiring and processing the ALS data and Nuru Hussein and the rest of the field crew for field data collection.

\section{Author Contributions}

Endre Hofstad Hansen has been the main author of the manuscript, carried out and supervised the field work and performed the calculations and analysis. Terje Gobakken has prepared the remote sensing data, co-authored and revised the manuscript. Ole Martin Bollandsås has planned and prepared the field data and revised parts of the manuscript. Eliakimu Zahabu has planned and supervised the study. Erik Næsset has planned and supervised the study and revised parts of the manuscript.

\section{Conflicts of Interest}

The authors declare no conflict of interest.

\section{References}

1. Lewis, S.L.; Sonké, B.; Sunderland, T.; Begne, S.K.; Lopez-Gonzalez, G.; van der Heijden, G.M.F.; Phillips, O.L.; Affum-Baffoe, K.; Baker, T.R.; Banin, L.; et al. Above-ground biomass and structure of 260 African tropical forests. Philos. Trans. Royal Soc. B Biol. Sci. 2013, 368, doi:10.1098/rstb.2012.0295.

2. Bastiaanssen, W.; Noordman, E.; Pelgrum, H.; Davids, G.; Thoreson, B.; Allen, R. SEBAL model with remotely sensed data to improve water-resources management under actual field conditions. J. Irrig. Drain. Eng. 2005, 131, 85-93.

3. De Jong, S.M.; Jetten, V.G. Estimating spatial patterns of rainfall interception from remotely sensed vegetation indices and spectral mixture analysis. Int. J. Geogr. Inf. Sci. 2007, 21, 529-545.

4. Doherty, R.M.; Sitch, S.; Smith, B.; Lewis, S.L.; Thornton, P.K. Implications of future climate and atmospheric $\mathrm{CO}_{2}$ content for regional biogeochemistry, biogeography and ecosystem services across East Africa. Glob. Change Biol. 2010, 16, 617-640.

5. ITTO (International Tropical Timber Organization). Annual Report 2012; ITTO: Yokohama, Japan, 2012.

6. Masera, O.; Ghilardi, A.; Drigo, R.; Angel Trossero, M. WISDOM: A GIS-based supply demand mapping tool for woodfuel management. Biomass Bioenergy 2006, 30, 618-637.

7. UNFCCC. Report of the Conference of the Parties on Its Sixteenth Session, Held in Cancun from 29 November to 10 December 2010. Addendum. Part Two: Action Taken by the Conference of the Parties at Its Sixteenth Session; United Nations Office: Geneva, Switzerland, 2011; p. 31. 
8. UNFCCC. Outcome of the Work of the Ad Hoc Working Group on Long-Term Cooperative Action under the Convention-C. Policy Approaches and Positive Incentives on Issues Relating to Reducing Emissions from Deforestation and Forest Degradation in Developing Countries and the Role of Conservation, Sustainable Management of Forests and Enhancement of Forest Carbon Stocks in Developing Countries; United Nations Office: Geneva, Switzerland, 2010.

9. UNFCCC. Report of the Conference of the Parties on Its Fifteenth Session, Held in Copenhagen from 7 to 19 December 2009. Addendum. Part Two: Action taken by the Conference of the Parties at Its Fifteenth Session; United Nations Office: Geneva, Switzerland, 2010; p. 43.

10. UNFCCC. Good Practice Guidance and Adjustments Under Article 5, Paragraph 2, of the Kyoto Protocol; FCCC/KP/CMP/2005/8/Add.3 Decision 20/CMP.1; United Nations Office: Geneva, Switzerland, 2006.

11. Grassi, G.; Monni, S.; Federici, S.; Achard, F.; Mollicone, D. Applying the conservativeness principle to REDD to deal with the uncertainties of the estimates. Environ. Res. Lett. 2008, 3, doi:10.1088/1748-9326/3/3/035005.

12. Gibbs, H.K.; Brown, S.; Niles, J.O.; Foley, J.A. Monitoring and estimating tropical forest carbon stocks: making REDD a reality. Environ. Res. Lett. 2007, 2, doi:10.1088/1748-9326/2/4/045023.

13. Plugge, D.; Baldauf, T.; Köhl, M. Reduced Emissions from Deforestation and Forest Degradation (REDD): Why a robust and transparent Monitoring, Reporting and Verification (MRV) System is mandatory. In Climate Change-Research and Technology for Adaptation and Mitigation; Blanco, J., Ed. InTech: Rijeka, Croatia, 2011; pp. 155-170.

14. GOFC-GOLD. A sourcebook of methods and procedures for monitoring and reporting anthropogenic greenhouse gas emissions and removals associated with deforestation, gains and losses of carbon stocks in forests remaining forests, and forestation. In GOFC-GOLD Report Version COP18-1; GOFC-GOLD Land Cover Project Office, Wageningen University: Wageningen, The Netherlands, 2012; p. 219.

15. Fassnacht, F.E.; Hartig, F.; Latifi, H.; Berger, C.; Hernández, J.; Corvalán, P.; Koch, B. Importance of sample size, data type and prediction method for remote sensing-based estimations of aboveground forest biomass. Remote Sens. Environ. 2014, 154, 102-114.

16. Zolkos, S.G.; Goetz, S.J.; Dubayah, R. A meta-analysis of terrestrial aboveground biomass estimation using lidar remote sensing. Remote Sens. Environ. 2013, 128, 289-298.

17. Koch, B. Status and future of laser scanning, synthetic aperture radar and hyperspectral remote sensing data for forest biomass assessment. ISPRS-J. Photogramm. Remote Sens. 2010, 65, 581-590.

18. McRoberts, R.E.; Tomppo, E.O.; Næsset, E. Advances and emerging issues in national forest inventories. Scand. J. Forest Res. 2010, 25, 368-381.

19. Clark, M.L.; Roberts, D.A.; Ewel, J.J.; Clark, D.B. Estimation of tropical rain forest aboveground biomass with small-footprint lidar and hyperspectral sensors. Remote Sens. Environ. 2011, 115, 2931-2942.

20. Asner, G.P.; Clark, J.K.; Mascaro, J.; Galindo García, G.A.; Chadwick, K.D.; Navarrete Encinales, D.A.; Paez-Acosta, G.; Cabrera Montenegro, E.; Kennedy-Bowdoin, T.; Duque, Á.; et al. High-resolution mapping of forest carbon stocks in the Colombian Amazon. Biogeosciences Discuss. 2012, 9 , 2445-2479. 
21. Mascaro, J.; Asner, G.P.; Muller-Landau, H.C.; van Breugel, M.; Hall, J.; Dahlin, K. Controls over aboveground forest carbon density on Barro Colorado Island, Panama. Biogeosciences. 2011, $8,1615-1629$.

22. Vincent, G.; Sabatier, D.; Blanc, L.; Chave, J.; Weissenbacher, E.; Pélissier, R.; Fonty, E.; Molino, J.-F.; Couteron, P. Accuracy of small footprint airborne LiDAR in its predictions of tropical moist forest stand structure. Remote Sens. Environ. 2012, 125, 23-33.

23. Asner, G.P.; Powell, G.V. N.; Mascaro, J.; Knapp, D.E.; Clark, J.K.; Jacobson, J.; Kennedy-Bowdoin, T.; Balaji, A.; Paez-Acosta, G.; Victoria, E.; Secada, L.; Valqui, M.; Hughes, R.F. High-resolution forest carbon stocks and emissions in the Amazon. Proc. Natl. Acad. Sci. USA 2010, 107, 16738-16742.

24. Hou, Z.; Xu, Q.; Tokola, T. Use of ALS, Airborne CIR and ALOS AVNIR-2 data for estimating tropical forest attributes in Lao PDR. ISPRS-J. Photogramm. Remote Sens. 2011, 66, 776-786.

25. Asner, G.P.; Clark, J.; Mascaro, J.; Vaudry, R.; Chadwick, K.D.; Vieilledent, G.; Rasamoelina, M.; Balaji, A.; Kennedy-Bowdoin, T.; Maatoug, L.; et al. Human and environmental controls over aboveground carbon storage in Madagascar. Carbon Balance Manag. 2012, 7, doi:10.1186/1750-0680-7-2.

26. Næsset, E. Predicting forest stand characteristics with airborne scanning laser using a practical two-stage procedure and field data. Remote Sens. Environ. 2002, 80, 88-99.

27. Næsset, E.; Gobakken, T. Estimation of above- and below-ground biomass across regions of the boreal forest zone using airborne laser. Remote Sens. Environ. 2008, 112, 3079-3090.

28. Hollaus, M.; Wagner, W.; Schadauer, K.; Maier, B.; Gabler, K. Growing stock estimation for alpine forests in Austria: A robust lidar-based approach. Can. J. For. Res. 2009, 39, 1387-1400.

29. Lefsky, M.A.; Cohen, W.B.; Harding, D.J.; Parker, G.G.; Acker, S.A.; Gower, S.T. Lidar remote sensing of above-ground biomass in three biomes. Glob. Ecol. Biogeogr. 2002, 11, 393-399.

30. Asner, G.P.; Mascaro, J.; Muller-Landau, H.C.; Vieilledent, G.; Vaudry, R.; Rasamoelina, M.; Hall, J.S.; van Breugel, M. A universal airborne LiDAR approach for tropical forest carbon mapping. Oecologia 2012, 168, 1147-1160.

31. Wang, W.F.; Lei, X.D.; Ma, Z.H.; Kneeshaw, D.D.; Peng, C.H. Positive relationship between aboveground carbon stocks and structural diversity in spruce-dominated forest stands in New Brunswick, Canada. For. Sci. 2011, 57, 506-515.

32. Kebede, M.; Kanninen, M.; Yirdaw, E.; Lemenih, M. Vegetation structural characteristics and topographic factors in the remnant moist Afromontane forest of Wondo Genet, south central Ethiopia. J. For. Res. 2013, 24, 419-430.

33. Bastin, J.-F.; Barbier, N.; Couteron, P.; Adams, B.; Shapiro, A.; Bogaert, J.; De Cannière, C. Aboveground biomass mapping of African forest mosaics using canopy texture analysis: Toward a regional approach. Ecol. Appl. 2014, 24, 1984-2001.

34. Bohlin, J.; Wallerman, J.; Fransson, J.E.S. Forest variable estimation using photogrammetric matching of digital aerial images in combination with a high-resolution DEM. Scand. J. For. Res. 2012, 27, 692-699.

35. Lim, K.S.; Treitz, P.M. Estimation of above ground forest biomass from airborne discrete return laser scanner data using canopy-based quantile estimators. Scand. J. For. Res. 2004, 19, 558-570. 
36. Li, Y.Z.; Andersen, H.E.; McGaughey, R. A comparison of statistical methods for estimating forest biomass from light detection and ranging data. West. J. Appl. For. 2008, 23, 223-231.

37. Boudreau, J.; Nelson, R.F.; Margolis, H.A.; Beaudoin, A.; Guindon, L.; Kimes, D.S. Regional aboveground forest biomass using airborne and spaceborne LiDAR in Quebec. Remote Sens. Environ. 2008, 112, 3876-3890.

38. D’Oliveira, M.V.N.; Reutebuch, S.E.; McGaughey, R.J.; Andersen, H.E. Estimating forest biomass and identifying low-intensity logging areas using airborne scanning lidar in Antimary State Forest, Acre State, Western Brazilian Amazon. Remote Sens. Environ. 2012, 124, 479-491.

39. Feldpausch, T.R.; Banin, L.; Phillips, O.L.; Baker, T.R.; Lewis, S.L.; Quesada, C.A.; Affum-Baffoe, K.; Arets, E.; Berry, N.J.; Bird, M.; et al. Height-diameter allometry of tropical forest trees. Biogeosciences 2011, 8, 1081-1106.

40. Myers, N.; Mittermeier, R.A.; Mittermeier, C.G.; da Fonseca, G.A.B.; Kent, J. Biodiversity hotspots for conservation priorities. Nature 2000, 403, 853-858.

41. Burgess, N.D.; Butynski, T.M.; Cordeiro, N.J.; Doggart, N.H.; Fjeldsa, J.; Howell, K.M.; Kilahama, F.B.; Loader, S.P.; Lovett, J.C.; Mbilinyi, B.; et al. The biological importance of the Eastern Arc Mountains of Tanzania and Kenya. Biol. Conserv. 2007, 134, 209-231.

42. Dawson, W.; Mndolwa, A.S.; Burslem, D.; Hulme, P.E. Assessing the risks of plant invasions arising from collections in tropical botanical gardens. Biodivers. Conserv. 2008, 17, 1979-1995.

43. Newmark, W.D. Conserving Biodiversity in East African Forests: A Study of the Eastern Arc Mountains; Springer: Berlin, Germany, 2002; p. 197.

44. Hamilton, A.C.; Bensted-Smith, R. Forest conservation in the East. Usambara Mountains, Tanzania; IUCN-The World Conservation Union; Forest Division, Ministry of Lands, Natural Resources, and Tourism, United Republic of Tanzania: Dar es Salaam, Tanzania and Gland, Switzerland and Cambridge, UK, 1989; p. 392.

45. Frontier Tanzania. Amani Nature Reserve: A biodiversity survey; Forestry and Beekeeping Division and Metsähallitus Consulting: Dar es Salaam, Tanzania and Vantaa, Finland, 2001.

46. Mpanda, M.M.; Luoga, E.J.; Kajembe, G.C.; Eid, T. Impact of forestland tenure changes on forest cover, stocking and tree species diversity in Amani Nature Reserve, Tanzania. For. Trees Livelihoods 2011, 20, 215-229.

47. Mgumia, F. Implications of Forestland Tenure Reforms on Forest Conditions, Forest Govenance, and Community Livelihoods at Amani Nature Reserve. Ph.D. Thesis, Sokoine University of Agriculture, Tanzania, 2014; pp. 280.

48. Marshall, A.R.; Willcock, S.; Platts, P.J.; Lovett, J.C.; Balmford, A.; Burgess, N.D.; Latham, J.E.; Munishi, P.K.T.; Salter, R.; Shirima, D.D.; et al. Measuring and modelling above-ground carbon and tree allometry along a tropical elevation gradient. Biol. Conserv. 2012, 154, 20-33.

49. Henry, M.; Besnard, A.; Asante, W.A.; Eshun, J.; Adu-Bredu, S.; Valentini, R.; Bernoux, M.; Saint-Andre, L. Wood density, phytomass variations within and among trees, and allometric equations in a tropical rainforest of Africa. For. Ecol. Manag. 2010, 260, 1375-1388.

50. Mehtatalo, L. Forest Biometrics Functions of Lauri Mehtatalo, R Package Version 1.1. Available online: http://cs.uef.fi/ lamehtat/rcodes (accessed on 9 January 2015).

51. $\mathrm{R}$ Development Core Team. R: A language and environment for statistical computing; $\mathrm{R}$ Foundation for Statistical Computing: Vienna, Austria, 2013. 
52. Prodan, M. Forest Biometrics; Pergamon Press: Oxford, UK, 1968; p. 447.

53. Pinheiro, J.; Bates, D.; DebRoy, S.; Sarkar, D.; R Development Core Team. nlme: Linear and Nonlinear Mixed Effects Models. R Package Version 3.1-115. Available online: http://cran.rproject.org/src/contrib/Archive/nlme (accessed on 9 January 2015).

54. Lappi, J.; Bailey, R.L. A height prediction model with random stand and tree parameters-An alternative to traditional site index methods. For. Sci. 1988, 34, 907-927.

55. Masota, A.M.; Zahabu, E.; Malimbwi, R.; Bollandsås, O.M.; Eid, T. Tree allometric models for above- and belowground biomass of tropical rainforests in Tanzania. Southern For. A J. For. Sci. 2015, submitted.

56. Kouba, J. A Guide to Using International Gnss Service (Igs) Products; IGS Central Bureau, Jet Propulsion Laboratory: Pasadena, CA, USA, 2009; p. 34.

57. Anon. Pinnacle User's Manual; Javad Positioning Systems: San Jose, CA, USA, 1999.

58. Næsset, E. Effects of differential single- and dual-frequency GPS and GLONASS observations on point accuracy under forest canopies. Photogramm. Eng. Remote Sens. 2001, 67, 1021-1026.

59. Axelsson, P. DEM generation from laser scanner data using adaptive TIN models. Int. Arch. Photogramm. Remote Sens. 2000, 33, 110-117.

60. Anon. Terrascan User's Guide; Terrasolid Oy: Jyvaskyla, Finland, 2012; p. 311.

61. Anon. LAS specification, Version 1.2; American Society for Photogrammetry and Remote Sensing (ASPRS): Bethesda, MA, USA, 2008; p. 13.

62. Nilsson, M. Estimation of tree heights and stand volume using an airborne lidar system. Remote Sens. Environ. 1996, 56, 1-7.

63. Haralick, R.M.; Shanmugam, K.; Dinsteein, I.H. Textural features for image classification. IEEE Trans. Syst. Man Cybern. 1973, 3, 610-621.

64. Zvoleff, A. Calculate Textures from Grey-Level Co-Occurrence Matrices (Glcms) In R, R Package Version 0.3.1. Available online: http://cran.r-project.org/src/contrib/Archive/glmc (accessed on 9 January 2015).

65. Goldberger, A. Interpretation and estimation of Cobb-Douglas functions. Econometrica 1968, 36, 464-472.

66. Gregoire, T.G.; Lin, Q.F.; Boudreau, J.; Nelson, R. Regression estimation following the square-root transformation of the response. For. Sci. 2008, 54, 597-606.

67. Lumley, T.; Miller, A. Leaps: Regression Subset Selection, R Package Version 2.9. Available online: http://cran.r-project.org/src/contrib/Archive/leaps (accessed on 9 January 2015).

68. Tomppo, E.; Katila, M.; Mäkisara, K.; Peräsaari, J.; Malimbwi, R.; Chamuya, N.; Otieno, J.; Dalsgaard, S.; Leppänen, M. A Report to the Food and Agriculture Organization of the United Nations (FAO) in Support of Sampling Study for National Forestry Resources Monitoring and Assessment (NAFORMA) in Tanzania. Available online: http:/www.mp-discussion.org/ NAFORMA.pdf (accessed on 10 March 2010).

69. Freitas, J.; Oliveira, Y.M.D.; Rosot, M.A.; Gomide, G.; Mattos, P. Development of the national forest inventory of Brazil. In National Forest Inventories: Pathways for Common Reporting; Tomppo, E., Gschwantner, T., Lawrence, M., McRoberts, R.E., Eds.; Springer: Heidelberg, Germany, 2010; pp. 89-95. 
70. Laurance, S.G.W.; Laurance, W.F.; Nascimento, H.E.M.; Andrade, A.; Fearnside, P.M.; Expedito, R.G.R.; Condit, R. Long-term variation in Amazon forest dynamics. J. Veg. Sci. 2009, 20, 323-333.

71. Means, J.E.; Acker, S.A.; Harding, D.J.; Blair, J.B.; Lefsky, M.A.; Cohen, W.B.; Harmon, M.E.; McKee, W.A. Use of large-footprint scanning airborne lidar to estimate forest stand characteristics in the Western Cascades of Oregon. Remote Sens. Environ. 1999, 67, 298-308.

72. Gobakken, T.; Næsset, E. Assessing effects of positioning errors and sample plot size on biophysical stand properties derived from airborne laser scanner data. Can. J. For. Res. 2009, 39, 1036-1052.

73. Mascaro, J.; Detto, M.; Asner, G.P.; Muller-Landau, H.C. Evaluating uncertainty in mapping forest carbon with airborne LiDAR. Remote Sens. Environ. 2011, 115, 3770-3774.

74. McRoberts, R.E.; Andersen, H.E.; Næsset, E. Using Airborne Laser Scanning data to support forest sample surveys. In Forestry Applications of Airborne Laser Scanning; Maltamo, M., Næsset, E., Vauhkonen, J., Eds.; Springer Netherlands: Burlin, Germany, 2014; Volumn 27, pp. 269-292.

75. Mugasha, W.; Bollandsås, O.M.; Eid, T. Relationships between diameter and height of trees in natural tropical forest in Tanzania. Southern For A J. For. Sci. 2013, 75, 221-237.

76. Valbuena, R.; Mauro, F.; Rodriguez-Solano, R.; Manzanera, J.A. Accuracy and precision of GPS receivers under forest canopies in a mountainous environment. Span. J. Agric. Res. 2010, 8, $1047-1057$.

77. Li, W.; Niu, Z.; Gao, S.; Huang, N.; Chen, H. Correlating the horizontal and vertical distribution of lidar point clouds with components of biomass in a picea crassifolia forest. Forests 2014, 5, 1910-1930.

78. Pippuri, I.; Kallio, E.; Maltamo, M.; Peltola, H.; Packalen, P. Exploring horizontal area-based metrics to discriminate the spatial pattern of trees and need for first thinning using airborne laser scanning. Forestry 2012, 85, doi:10.1093/forestry/cps005.

79. Iida, Y.; Kohyama, T.S.; Kubo, T.; Kassim, A.; Poorter, L.; Sterck, F.; Potts, M.D. Tree architecture and life-history strategies across 200 co-occurring tropical tree species. Funct. Ecol. 2011, 25, 1260-1268.

80. Poorter, L.; Bongers, L.; Bongers, F. Architecture of 54 moist-forest tree species: Traits, trade-offs, and functional groups. Ecology 2006, 87, 1289-1301.

81. Skowronski, N.; Clark, K.; Nelson, R.; Hom, J.; Patterson, M. Remotely sensed measurements of forest structure and fuel loads in the Pinelands of New Jersey. Remote Sens. Environ. 2007, 108, $123-129$.

(C) 2015 by the authors; licensee MDPI, Basel, Switzerland. This article is an open access article distributed under the terms and conditions of the Creative Commons Attribution license (http://creativecommons.org/licenses/by/4.0/). 